\title{
К ВОПРОСУ О КОМПЕТЕНЦИИ ЗАКОНОДАТЕЛЬНЫХ (ПРЕДСТАВИТЕЛЬНЫХ) ОРГАНОВ ГОСУДАРСТВЕННОЙ ВЛАСТИ СУБЪЕКТОВ РОССИЙСКОЙ ФЕДЕРАЦИИ
}

Аннотация: Предмет исследования составляют правовые нормы, включая положения Конституиии Российской Федерации, действующего законодательства как на федеральном уровне, так и на региональном (конституции (уставы)), законы, регламентируюшие вопросы осуществления конституционно закрепленных в рамках предметов ведения Федерачии и ее субъектов полномочий законодательного (представительного) органа государственной власти субъектов Российской Федеращии, иные источники права, практика реализации полномочий региональными парламентами исходя из природы и функционального предназначения законодательных (представительных) органов государственной власти субъектов Российской Федерачии, научные идеи, изложенные в правовой доктрине. Основными методами являются общенаучные (диалектический, системный) и частноправовые (сравнительноправовой, формально-юридический) методы. Использование данных методов позволило выявить основные проблемы, связанные с осуществлением полномочий законодательными (представительными) органами государственной власти субъектов РФ. Научная новизна заключается в попытке комплексного конституционно-правового исследования вопросов осуществления и проблем реализации полномочий законодательных (представительных) органов государственной власти субъектов Федерации. В работе делается акиент на несовершенство действующего законодательства в сфере правового регулирования законодательных полномочий парламентов субъектов по предметам совместного ведения. Вносятся предложения по совершенствованию механизма реализации контрольных полномочий законодательных (представительных) органов государственной власти субъектов РФ.

Abstract: The object of studies involves legal norms, including the provisions of the Constitution of the Russian Federation, the current federal and regional legislation (constitutions, statutes, laws regulating the issues of implementation of activities within constitutionally provided competence of the Federation and its constituent subjects by the legislative (representative) government bodies of the constituent subjects of the Russian Federation, other sources of law, practice of implementation of competence by the regional parliaments based upon the nature and functional purpose of the legislative (representative) government bodies of the constituent subjects of the Russian Federation, scientific ideas, as provided for by the legal doctrine. The main methods involve general scientific methods (dialectic, systemic), specific legal methods (comparative legal studies, formal legal method). The use of these methods has allowed to single out the main problems regarding implementation of competence of legislative (representative) government bodies of the constituent subjects of the Russian Federation. The scientific novelty is due to the attempt of complex constitutional legal study of the issues of implementation of legislative (representative) state government bodies of the constituent subjects of the Russian Federation and related problems. The article pays special attention to the imperfections of the current legislation in the sphere of legal regulation of legislative competence of parliaments of the constituent subjects in the spheres of joint competence. The authors make propositions for the improvement of the mechanism of implementation of the control competence of the legislative (representative) government bodies of the constituent subjects of the Russian Federation. Ключевые слова: предметы ведения, законодательные (представительные) органы, компетенция, разграничение, субъекты, Федерация, законодательство, законотворческие полномочия, механизм ответственности, парламентский контроль. Keywords: objects of competence, legislative (representative) bodies, competence, distinguishing, constituent subjects, federation, legislation, law-making competence, responsibility mechanism, parliamentary control.

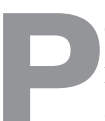

оссийская Конституция для обозначения законодательного органа субъекта Российской Федерации использует два понятия: «законодательный орган государственной власти» и «представительный орган государственной власти». В статьях 125 (ч. 2) и 136 Конституции РФ говорится о законодательном органе государственной власти субъекта Федерации, в ст. 77 (ч. 1) - о представительных органах государственной власти. Иногда эти термины используются как синонимы ${ }^{1}$.

При этом надо сказать, что в отличие от других федеральных конституций, в российской Конституции

\footnotetext{
${ }^{1}$ Шабанов Х.М. Законодательные (представительные) органы государственной власти республик-субъектов Российской Федерации: дис. ... канд. юрид. наук. Махачкала, 2004.
} 


\section{Право и политика $6(174) \cdot 2014$}

не содержатся нормы, определяющие основы организации органов государственной власти субъектов РФ. Установление общих принципов организации системы органов государственной власти, согласно пункту «н» ст. 72 Конституции России, находится в сфере совместного ведения Федерации и субъектов РФ ${ }^{2}$. В соответствии с частью 1 ст. 77 Конституции система органов государственной власти субъектов РФ устанавливается ими самостоятельно - согласно основам конституционного строя РФ и общим принципам организации представительных и исполнительных органов государственной власти, установленным федеральным законом.

Федеральный закон от 06.10.1999 г. постоянно действующим высшим и единственным органом законодательной власти субъекта Федерации определяет законодательный (представительный) орган. К его основным полномочиям закон относит: принятие конституции (устава) субъекта Федерации, а также поправок к ней (нему); осуществление законодательного регулирования по предметам ведения субъекта РФ и предметам совместного ведения РФ и субъектов РФ в пределах полномочий субъекта; заслушивание ежегодных отчетов высшего должностного лица субъекта Федерации о результатах деятельности высшего исполнительного органа, в том числе по вопросам, поставленным законодательным органом субъекта РФ, а также осуществление иных полномочий, установленных Конституцией РФ, настоящим Законом, другими законами, конституцией (уставом) и законами субъекта ${ }^{3}$. По сути, вышеприведенные положения раскрывают юридическую природу и функциональное предназначение данного органа власти. В литературе эти укрупненные полномочия определяются как законодательные, представительские, контрольные и учредительские 4 .

Право субъектов принимать учредительные акты закреплено в Конституции РФ, в соответствии с положениями которой определены виды и способы их принятия.

\footnotetext{
${ }^{2}$ Павлушкин А.В. Компетенция законодательного (представительного) органа государственной власти субъекта Российской Федерации: дис. ... канд. юрид. наук. М., 2001.

${ }^{3}$ Об общих принципах организации законодательных (представительных) и исполнительных органов государственной власти субъекта РФ: федер. закон Рос. Федерации от 6 октября 1999 г. (с изм. и доп.), ст. 5. Доступ из справ. - правовой системы «КонсультантПлюс».

${ }^{4}$ См.: Котелевская И.В. Современный парламент // Государство и право. 1997. № 3. С.9; Лебедев В.А. Проблемы организации и деятельности законодательной и исполнительной власти в субъектах РФ: автореф. дис. ... д-ра юрид. наук. М., 2000. С. 25.
}

Осуществление полномочий законодательного характера также находятся в прямой взаимосвязи с конституционными нормами, закрепляющими модель разграничения предметов ведения между Федерацией и ее субъектами.

Однако заметим, что отношение к установлению предметов совместного ведения, сложившееся в научной литературе, является зачастую диаметрально противоположным - от признания ст. 72 Конституции России как нового слова в мировой практике федерализма до полного неприятия этой статьи и ее оценки как свидетельства неспособности законодателя разделить власть между Федерацией и ее субъектами ${ }^{5}$.

Подчеркнем, что в Конституции РФ не установлены нормы и процедуры, которые позволяют определить, что в сфере совместного ведения относится к полномочиям Федерации и что, соответственно, составляет полномочия субъектов Федерации. Вместе с тем, попытка федерального законодателя конкретизировать конституционные положения ст. 72 Конституции посредством законодательного закрепления принципов разграничения полномочий, в том числе в сфере совместного ведения, не привела к ожидаемым результатам 6 .

Во-первых, положения Закона, закрепляющие общие принципы разграничения полномочий между федеральными органами государственной власти и органами государственной власти субъектов РФ, сами нуждаются в детализации, т.к. их реализация предусматривает дополнительную нормативную регламентацию. Например, ст. 26.1 предполагает принятие целого комплекса нормативных правовых актов, в соответствии с которыми и должны быть определены конкретные полномочия региональных органов государственной власти, включая права, обязанности, ответственность, порядок и источники финансирования и т.д.

Подобная громоздкость, а главное, неопределенность в объеме и порядке осуществления полномочий

\footnotetext{
${ }^{5}$ Кандалов П.М. Проблемы законодательного регулирования предметов совместного ведения Российской Федерации и ее субъектов // Конституционное и муниципальное право. 2006. № 10.

${ }^{6}$ См.: Обеспечение единого правового пространства Российской Федерации: мониторинг регионального законодательства: отчет о деятельности Центра регионального законодательства при ФГБОУ ВПО «Дагестанский государственный университет» / под ред. канд. юрид. наук, доц. Д.Ш. Пирбудаговой. Махачкала: ИПЦ ДГУ, 2011. С. 11.

${ }^{7}$ См.: Об общих принципах организации законодательных (представительных) и исполнительных органов государственной власти субъекта РФ: федер. закон Рос. Федерации от 6 октября 1999 г. (с изм. и доп.), ст. 26.1, 26.3-1. Доступ из справ. - правовой системы «КонсультантПлюс».
} 
на практике порождает ряд проблем, в числе которых возможность договорных разграничений полномочий между Федерацией и отдельными субъектами. Данное обстоятельство, вопреки расхожему мнению о том, что нет и не может быть полной четкости в разграничении нормотворческой компетенции и полномочий между Федерацией и ее субъектами ${ }^{8}$, в действительности негативно сказывается на всем комплексе отношений между Федерацией и субъектами.

Во-вторых, принципы финансового обеспечения осуществления полномочий органами государственной власти субъектов, при действующем бюджетном регулировании отношений, фактически обнуляют возможность осуществления законодательными (представительными) органами полномочий нормотворческого характера.

Что же касается иных полномочий, выделенных в литературе, то следует обратить внимание на контрольную группу полномочий законодательных (представительных) органов государственной власти субъектов, поскольку именно парламентский контроль выступает индикатором демократичности государственной власти в целом.

Конституциями отдельных субъектов Федерации прямо предусматривается наличие контрольных полномочий у законодательных (представительных) органов государственной власти. К ним относят право законодательного органа принимать участие в формировании высшего исполнительного органа, высшего должностного лица субъекта РФ99 , в утверждении (или согласовании) назначения на должности некоторых должностных лиц высшего исполнительного органа субъекта РФ, в согласовании назначения на должность руководителей территориальных органов федеральных органов исполнительной власти в случаях, предусмотренных в федеральном законе. Подчеркнем, что формы такого участия по отношению к руководителям территориальных органов федеральных органов исполнительной власти устанавливает федеральный закон, в остальных случаях - конституции (уставы) и закон субъекта ${ }^{10}$.

\footnotetext{
8 Золотухина Т.A. Влияние федерального центра на законотворчество в регионах // Наука и образование: хозяйство и экономика; предпринимательство; право и управление. 2012. № 7 (26).

${ }^{9}$ Конституция Республики Дагестан (п. 10, ч. 1 ст. 68). Махачкала, 2013; О порядке избрания главы Республики Дагестан депутатами Народного Собрания Республики Дагестан: закон Республики Дагестан от 6 июня.2013 г. № 29: в ред. от 30 декабря.2013 г. // Собр. законодательства Респ. Дагестан. 2013. № 11, ст. 719.

${ }^{10}$ Об общих принципах организации законодательных (представительных) и исполнительных органов государственной власти субъекта РФ: Федеральный закон от 6 октября 1999 г. (с изм. и доп.), ст. 24. Доступ из справ. - правовой системы «КонсультантПлюс».
}

Особо следует обратить внимание на создание специальных контрольно-счетных органов субъектов РФ, в формировании которых законодательные (представительные) органы государственной власти принимают непосредственное участие ${ }^{11}$. Более того, подотчетность данных органов непосредственно создает региональному парламенту необходимые условия для эффективного функционирования системы «сдержек и противовесов» в области основных вопросов государственного управления в субъекте Федерации.

В научной литературе в механизме реализации контрольных полномочий законодательных органов власти субъектов РФ наиболее значимыми и эффективными определяются следующие формы прямого контроля: парламентский запрос, депутатский запрос, парламентское расследование, рассмотрение отчетов должностных лиц и органов исполнительной власти ${ }^{12}$. Вместе с тем, с данной позицией можно согласиться лишь отчасти, поскольку, как показывает правоприменительная практика, реализация таких контрольных полномочий, как парламентское расследование, рассмотрение отчетов должностных лиц и органов исполнительной власти, малоэффективна. Справедливости ради надо отметить, что подобная ситуация характерна не только для регионального уровня власти, но и для федерального в целом. Представляется, что единственно возможным вариантом решения обозначенной проблемы должно стать законодательное закрепление механизма ответственности органов и должностных лиц по результатам осуществления контрольных полномочий законодательными органами государственной власти. Соответственно эффективность регионального парламентского контроля может быть обеспечена лишь при условии необходимой самостоятельности субъектов Российской Федерации в его регламентации и осуществлении ${ }^{13}$.

Таким образом, усиление роли федерального законодательства в регулировании вопросов совместного ведения, которое в значительной мере ограничивает возможности регионов, может привести к полному ис-

\footnotetext{
${ }^{11}$ Об общих принципах организации и деятельности конституционно-счетных органов субъектов РФ и муниципальных образований: Федеральный закон от 7 февраля 2011 г. №6-Ф3 (с изм. и доп. от 2 июля 2013 г.) // Собр. законодательства Рос. Федерации. 2011. № 7, ст. 903.

${ }^{12}$ Кузнецов А.В. Парламентский контроль в субъектах Российской Федерации: автореф. дис. ... канд. юрид. наук. М., 2001. С. 29.

${ }^{13}$ Азаров Д.В. Конституционно-правовое регулирование регионального парламентского контроля как механизма обеспечения разделения и взаимодействия властей в субъектах РФ: автореф. дис. ... канд. юрид. наук. М., 2014.
} 
DOI: $10.7256 / 1811-9018.2014 .6 .12265$

При цитировании этой статьи сноска на doi обязательна

\section{Право и политика $6(174) \cdot 2014$}

ключению законодательных возможностей субъектов Федерации в этой области и, как следствие, полной потере их самостоятельности. Поэтому в условиях реформирования всей системы публичной власти, в особенности это касается законодательной власти, поиск оптимальной модели соотношения федерального и регионального законодательства по предметам совместного ведения, четкое определение «пределов вмешательства» со стороны центра, является первоочередной задачей государственной политики Российской Федерации.

\section{Библиография:}

1. Шабанов Х.М. Законодательные (представительные) органы государственной власти республиксубъектов Российской Федерации: дис. ... канд. юрид. наук. Махачкала, 2004.

2. Павлушкин А.В. Компетенция законодательного (представительного) органа государственной власти субъекта Российской Федерации: дис. ... канд. юрид. наук. М., 2001.

3. Кудрявцев В.В.. О некоторых вопросах конституционно-правового регулирования права граждан и их объединений на участие в формировании представи-тельных органов муниципальных образований в Российской Федерации // Административное и муниципальное право. - 2014. - № 3. - С. 104-107. DOI: $10.7256 / 1999-2807.2014 .3 .10992$

4. Котелевская И.В. Современный парламент // Государство и право. 1997. № 3. С.9.

5. Лебедев В.А. Проблемы организации и деятельности законодательной и исполнительной власти в субъектах РФ: автореф. дис. ... д-ра юрид. наук. М., 2000. С. 25.

6. Кандалов П.М. Проблемы законодательного регулирования предметов совместного ведения Российской Федерации и ее субъектов // Конституционное и муниципальное право. 2006. № 10 .

7. Д.Ш. Пирбудагова. Обеспечение единого правового пространства Российской Федерации: мониторинг регионального законодательства: отчет о деятельности Центра регионального законодательства при ФГБОУ ВПО «Дагестанский государственный университет» / под ред. канд. юрид. наук, доц. Д.Ш. Пирбудаговой. Махачкала: ИПЦ ДГУ, 2011. С. 11.

8. А. В. Васильев. Демократия как форма взаимодействия органов государства и граждан в управлении делами общества в современной России // Политика и Общество. - 2012. - № 2. - С. 104-107.

9. Золотухина Т.А. Влияние федерального центра на законотворчество в регионах // Наука и образование: хозяйство и экономика; предпринимательство; право и управление. 2012. № 7 (26).

10. Цалиев А.М. Расширение роли субъектов Российской Федерации в государственной политике // NB: Вопросы права и политики. - 2013. - № 3. - C.21-94. DOI: 10.7256/2305-9699.2013.3.554. URL: http://e-notabene.ru/lr/article_554.html

11. Гончаров В.В. Роль принципа централизма и децентрализации в организации и деятельности государственного аппарата в Российской Федерации // NB: Экономика, тренды и управление. - 2014. № 1. - C.64-75. DOI: 10.7256/2306-4595.2014.1.2020. URL: http://e-notabene.ru/etc/article_2020.html

12. Глигич-Золотарева М.В. «Маятник» федерализма // NB: Проблемы общества и политики. - 2013. - № 4. - C.59-81. DOI: 10.7256/2306-0158.2013.4.581. URL: http://e-notabene.ru/pr/article_581.html

13. Кузнецов А.В. Парламентский контроль в субъектах Российской Федерации: автореф. дис. ... канд. юрид. наук. М., 2001. С. 29.

14. Азаров Д.В. Конституционно-правовое регулирование регионального парламентского контроля как механизма обеспечения разделения и взаимодействия властей в субъектах РФ: автореф. дис. ... канд. юрид. наук. М., 2014.

15. Цалиев А.М. Расширение роли субъектов Российской Федерации в государственной политике // NB: Вопросы права и политики. - 2013. - 3. -C. 21 -94. DOI: 10.7256/2305-9699.2013.3.554. URL: http://www.e-notabene.ru/lr/article_554.html

16. Н. М. Добрынин, М. В. Глигич-Золотарева Управление развитием федерации: прикладной системный анализ в сфере государственно- территориального устройства. Часть 4. Алгоритм решения системных проблем федерализма // Право и политика. - 2011. - 9. - С. 1414 - 1430.

\section{References (transliteration):}

1. Shabanov Kh.M. Zakonodatel'nye (predstavitel'nye) organy gosudarstvennoi vlasti respublik-sub"ektov Rossiiskoi Federatsii: dis. ... kand. yurid. nauk. Makhachkala, 2004.

2. Pavlushkin A.V. Kompetentsiya zakonodatel'nogo (predstavitel'nogo) organa gosudarstvennoi vlasti 
DOI: $10.7256 / 1811-9018.2014 .6 .12265$

При цитировании этой статьи сноска на doi обязательна

Власть и управление

sub" "ekta Rossiiskoi Federatsii: dis. ... kand. yurid. nauk. M., 2001.

3. Kudryavtsev V.V.. O nekotorykh voprosakh konstitutsionno-pravovogo regulirovaniya prava grazhdan i ikh ob"edinenii na uchastie $\mathrm{v}$ formirovanii predstavi-tel'nykh organov munitsipal'nykh obrazovanii v Rossiiskoi Federatsii // Administrativnoe i munitsipal'noe pravo. - 2014. - № 3. - S. 104-107. DOI: 10.7256/1999-2807.2014.3.10992

4. Kotelevskaya I.V. Sovremennyi parlament // Gosudarstvo i pravo. 1997. № 3. S.9.

5. Lebedev V.A. Problemy organizatsii i deyatel'nosti zakonodatel'noi i ispolnitel'noi vlasti v sub"ektakh RF: avtoref. dis. ... d-ra yurid. nauk. M., 2000. S. 25.

6. Kandalov P.M. Problemy zakonodatel'nogo regulirovaniya predmetov sovmestnogo vedeniya Rossiiskoi Federatsii i ee sub"ektov // Konstitutsionnoe i munitsipal'noe pravo. 2006. № 10.

7. D.Sh. Pirbudagova. Obespechenie edinogo pravovogo prostranstva Rossiiskoi Federatsii: monitoring regional'nogo zakonodatel'stva: otchet o deyatel'nosti Tsentra regional'nogo zakonodatel'stva pri FGBOU VPO «Dagestanskii gosudarstvennyi universitet»/ pod red. kand. yurid. nauk, dots. D.Sh. Pirbudagovoi. Makhachkala: IPTs DGU, 2011. S. 11.

8. A. V. Vasil'ev. Demokratiya kak forma vzaimodeistviya organov gosudarstva $\mathrm{i}$ grazhdan $\mathrm{v}$ upravlenii delami obshchestva v sovremennoi Rossii // Politika i Obshchestvo. - 2012. - № 2. - S. 104-107.

9. Zolotukhina T.A. Vliyanie federal'nogo tsentra na zakonotvorchestvo v regionakh // Nauka i obrazovanie: khozyaistvo i ekonomika; predprinimatel'stvo; pravo i upravlenie. 2012. № 7 (26).
10. Tsaliev A.M. Rasshirenie roli sub"ektov Rossiiskoi Federatsii v gosudarstvennoi politike // NB: Voprosy prava i politiki. - 2013. - № 3. - S.21-94. DOI: 10.7256/2305-9699.2013.3.554. URL: http://e-notabene. $\mathrm{ru} / \mathrm{lr} /$ article $554 . \mathrm{html}$

11. Goncharov V.V. Rol' printsipa tsentralizma i detsentralizatsii v organizatsii i deyatel'nosti gosudarstvennogo apparata v Rossiiskoi Federatsii // NB: Ekonomika, trendy i upravlenie. - 2014. - № 1. - S.64-75. DOI: 10.7256/2306-4595.2014.1.2020. URL: http://e-notabene.ru/etc/article_2020.html

12. Gligich-Zolotareva M.V. «Mayatnik» federalizma // NB: Problemy obshchestva i politiki. - 2013. - № 4. - S.59-81. DOI: 10.7256/2306-0158.2013.4.581. URL: http://e-notabene.ru/pr/article_581.html

13. Kuznetsov A.V. Parlamentskii kontrol' v sub"ektakh Rossiiskoi Federatsii: avtoref. dis. ... kand. yurid. nauk. M., 2001. S. 29.

14. Azarov D.V. Konstitutsionno-pravovoe regulirovanie regional'nogo parlamentskogo kontrolya kak mekhanizma obespecheniya razdeleniya i vzaimodeistviya vlastei v sub"ektakh RF: avtoref. dis. ... kand. yurid. nauk. M., 2014.

15. Tsaliev A.M. Rasshirenie roli sub"ektov Rossiiskoi Federatsii v gosudarstvennoi politike // NB: Voprosy prava i politiki. - 2013. - 3. - C. 21 - 94. DOI: 10.7256/2305-9699.2013.3.554. URL: http://www.enotabene.ru/lr/article_554.html

16. N. M. Dobrynin, M. V. Gligich-Zolotareva Upravlenie razvitiem federatsii: prikladnoi sistemnyi analiz v sfere gosudarstvenno- territorial'nogo ustroistva. Chast' 4 . Algoritm resheniya sistemnykh problem federalizma // Pravo i politika. - 2011. - 9. - C. 1414 - 1430. 